\title{
The Relative Contribution of Dietary Habits, Leisure-Time Exercise, Exercise Attitude, and Body Mass Index to Self-Rated Health among College Students in Taiwan
}

\author{
Huey-Hong Hsieh ${ }^{1}{ }^{*}$, Chia-Ming Chang ${ }^{2}$, Li-Wei Liu ${ }^{3}$ and Hsiu-Chin Huang ${ }^{4}$ \\ 1 Department of Leisure Management, Taiwan Shoufu University, Tainan 72153, Taiwan \\ 2 Department of Physical Education, Health \& Recreation, National Chiayi University, Chiayi 60004, Taiwan; \\ gr5166@yahoo.com.tw \\ 3 Department of Leisure Service Management, Chaoyang University of Technology, Taichung 41349, Taiwan; \\ ijofsrm@gmail.com \\ 4 Department of Tourism, Leisure, Entertainment Management, Tatung Institute of Technology, Chiayi 60044, \\ Taiwan; op5166@yahoo.com.tw \\ * Correspondence: nancylin809@gmail.com; Tel.: +886-912-687-406
}

Received: 8 March 2018; Accepted: 8 May 2018; Published: 11 May 2018

\begin{abstract}
Background: Self-rated health (SRH) is consistent with objective health status and can serve as a global measure of health status in the general population. The purpose of this study is to find the connections of dietary habits, leisure-time exercise, exercise attitude, and body mass index (BMI) to SRH among college students. Methods: The "dietary-exercise attitude and SRH" questionnaire was developed to investigate college students in Taiwan through the Internet. Partial least squares structural equation modeling (PLS-SEM) was used to test the relationship among them. Results: The reliability and validity were confirmed using PLS-SEM. The results found exercise habits, dietary habits, and BMI explained $26.5 \%$ of SRH. Poor dietary habits and being overweight led to bad health status (negative path coefficients to SRH). Additionally, the study found that positive exercise attitude had a positive relationship with exercise habits. Conclusions: Based on the results, college students should be well-informed of the potential threat of poor dietary habits and being overweight to health and should improve their attitude with respect to exercise so as to prevent overweight-related diseases.
\end{abstract}

Keywords: dietary habits; college students, leisure-time exercise; exercise attitude; body mass index; self-rated health

\section{Introduction}

With the prevalence of communication products, robots, sedentary lifestyles, and poor dietary habits, obesity is common among all age groups more than ever. Obesity is a major public health problem due to its increasing prevalence [1] and its associations with higher morbidity and mortality from multiple diseases [2,3].

In Chinese society, the emphasis on academic success is well known around the world. Most students only need to study hard and parents do the rest [4]. The focus of study causes the neglect of knowledge of healthy lifestyles, which in turn may lead to health problems. Upon coming to college, they need to take care of themselves. Studies $[5,6]$ of the changes of diet and exercise in Taiwan have shown the trends of poor dietary habits (e.g., consuming sugary drinks) and the decrease of leisure-time exercise. Without the parents' supervision of diet and lifestyle, being overweight or obese has become prevalent among college students in Taiwan [6]. 
Research has shown that self-rated health (SRH) is a good indicator of health [7]. In addition, Singh-Manoux et al. [8] found that the measure of physical and mental health contributes most to the SRH construct.

For many people, college is the last education before a career. Therefore, it is very important to cultivate good dietary and exercise habits during this period. The founder of the world's first and largest silicon foundry, Morris Chang, gave 11 admonitions to college students. The top one advises students "to develop a lifetime, healthy lifestyle" [9].

To better know the current status of students' perceptions of dietary habits, exercise habits, body mass index (BMI), and SRH, this study conducted a series of investigations on college students to identify the relationships of dietary habits, exercise attitude, exercise habits, BMI, and SRH among college students. The results potentially provide useful information for college students and administrators. Therefore, the study intended to answer the following questions: (1) Are the health behavior variables directly related to SRH? (2) Are the exercise attitude variables directly related to exercise habits? (3) Are the health behavior variables directly related to BMI? (4) Are the exercise habit variables directly related to BMI? (5) Is BMI directly related to SRH? (6) Does BMI mediate the relation of health behavior to SRH? (7) Do exercise habits mediate the relation of exercise attitude to SRH?

\subsection{Self-Rated Health}

$\mathrm{SRH}$, a subjective assessment of health status, is extensively used in the public health field. Research had found relevance of SRH and objective health status, and SRH is consistent with objective health status. Therefore, it can serve as a global measure of health status in the general population [9].

\subsection{Dietary Habits among College Students}

Poor eating habits are an important public health issue that has large health and economic implications. Many food preferences are established early, but because people make independent eating decisions more often as they move through adolescence, the transition to independent living during university is important $[10,11]$. We therefore investigated college students' dietary habits and examine the connections of the habits to BMI and SRH.

\subsection{Exercise Attitude and Exercise Habits}

Many studies have examined the connection between exercise belief and exercise habits [12]. Several studies have found that positive exercise attitude contributed to the maintenance of good exercise habits [13]. We further examined the relationships of exercise attitude to exercise habits and exercise habits to BMI and SRH.

\subsection{BMI and Self-Rated Health}

BMI is one of the most commonly used measures of obesity. The link between BMI and health shows that overweight or obese people are more likely than those at normal weight to have medical problems such as high blood pressure, diabetes, stroke, and cancer [14]. As Calle et al. [15] pointed out, the risk of death from all causes-cardiovascular disease, cancer, or other diseases-increases throughout the range of moderate and severe overweight conditions for both men and women in all age groups. Since BMI is used as a convenient index for health status, we will examine the link between BMI and SRH. 


\section{Materials and Methods}

\subsection{Participants}

The data for this study came from college students in Taiwan. We post a web-based questionnaire and used snowball sampling to invite college students to participate in the study. Two hundred seventy participants completed the investigation.

Since BMI is a key independent variable in the study, students who had not answered the self-reported height and weight measurements were excluded from the study. Therefore, 238 remained in the study, with $121(50.8 \%)$ male and 117 (49.2\%) female students.

\subsection{Measures}

Exercise Attitude (EA). The "Exercise Attitude for College Students Scale" developed by Yang \& $\mathrm{Ku}$ [16] was used to measure respondents' exercise attitude on a five-point Likert scale $(1=$ "strongly disagree" to $5=$ "strongly agree"). One item asked respondents whether they agree with "Exercise is good for health". Reliability of the scale is acceptable with a Cronbach's $\alpha$ of 0.83 .

Exercise Habits (EH). The engagement of exercise can be accessed by one's "frequency", "duration", and "intensity" of exercise involvement in a certain period [17]. In this study, college students' exercise habits were measured by "frequency", "duration", "intensity", and "seriousness" of their exercise habits on a five-point Likert scale $(1=$ "never" to $5=$ "always"). In one item, students were asked if they do exercise at least 3 times and 30 min a week.

BMI. BMI was measured by asking respondents to self-report their weight and height. BMI was calculated using the weight (in kilograms) divided by the height squared (in meters).

Dietary Habits. The "Dietary Habits Scale" developed by Huang [18] was used to measure the dietary habits with Cronbach's $\alpha$ of 0.85 . There were seven good dietary habits (GDHs) on the scale. To measure if respondents consumed a good diet, we used the variable labeled "good diet". One item was to ask respondents to self-report how often in one week they ate "vegetables". The response format was 1 = almost never, 2 = less than once a week, $3=$ every week, $4=$ once a day, and $5=$ more than once a day. There were nine poor dietary habits (PDH) on the scale. To measure if respondents consumed a poor diet, we used the variable labeled "poor diet". One item was to ask respondents self-report how often in one week they ate "fast food, e.g., hamburger, fries, hot dog". The response format was 1 = almost never, 2 = less than once a week, $3=$ every week, $4=$ once a day, and $5=$ more than once a day.

Self-rated Health (SRH). We used two items to measure self-rated health on a 5-point Likert scale ("poor", "fair", "good", "very good", "excellent"). One item was to self-report one's health status and the other was to compare one's health status with others among the same age [10].

\subsection{Design and Analysis}

Our analysis was based on partial least squares structural equation modeling (PLS-SEM) [19,20] and was conducted using SmartPLS 2.0 (SmartPLS GmbH, Hamburg, Germany) [21]. According to Pirouz [22], PLS can be used for exploratory and confirmatory analyses. PLS benefits from (1) being distribution-free, (2) requiring only a small sample size, (3) an ability to process multiple dependent and independent variables simultaneously, (4) an ability to handle collinearity, and (5) an ability to process both formative or reflective indicators. Our study aimed to identify the relationships between EA, EH, PDH, GDH, BMI, and SRH. Therefore, PLS-SEM was used to test the relationships in the study.

\section{Results}

\subsection{Descriptive Statistics}

The sample consisted of 50.8\% male and 49.2\% female. Average value of BMI equaled 23.15 $(\mathrm{SD}=4.66)$, which indicated a wide range of BMI variation among participants. The average value of 
EA equaled $3.81(\mathrm{SD}=0.69)$, which indicated a positive attitude toward exercise. The average value of EH equaled $3.07(\mathrm{SD}=0.95)$, which indicated the regular exercise habits of participants. The average value of PDH equaled $2.96(\mathrm{SD}=0.76)$, which indicated the regularity of college students' poor dietary habits . The average value of GDH equaled $3.34(\mathrm{SD}=0.74)$, which indicated that the frequency of GDH's intake was between once a week and once a day. The average value of SRH equaled 3.32 $(\mathrm{SD}=0.75)$, which indicated that the health status was between good and very good.

\subsection{Measurement Model}

The factor loadings from the final PLS measurement models are all greater than 0.70 on their respective factors, which was an indication of indicator reliability. Composite reliability $\left(\varrho_{\mathrm{c}}\right)$ [23] and Cronbach's alpha values for all scales exceeded the minimum threshold level of 0.70 [24], thus indicating the reliability of all scales used in this study (Table 1). Results revealed that the average variance extracted (AVE) for all factors exceeded the minimum threshold value of 0.50 , which was an indication of the convergent validity of all scales (Table 1). Fornell's and Larcker's test [25] for discriminant validity revealed relatively high variances extracted for each factor compared to the interscale correlations, which was an indication of the discriminant validity of the six constructs. Secondly, we evaluated the general adjustment indicator of the model. The goodness of fit (GoF) index is fundamentally an index that measures the projection and reliability of the measurement model. Specifically, it can be understood as the geometric mean of the average communality and the average $R^{2}$ of the endogenous latent variables [26,27]. Wetzels et al. [26] suggest that the value 0.36 is adequate for the areas of the social and behavioral sciences. Thus, doing this calculation with that value, we obtained 0.44 , indicating that the model had an adequate adjustment. Lastly, we evaluated the model fit of the PLS model, with the SRMR (Standardized Root Mean Square Residual) being 0.07 and the NFI (Normed fit index) being 0.94, indicating the adequacy of the model [23].

Table 1. Reliability, convergent, and discriminant validity of measurement model.

\begin{tabular}{lcccccccc}
\hline \multirow{2}{*}{ Construct } & \multicolumn{9}{c}{ Correlations } & \multirow{2}{*}{ CR $^{\mathbf{b}}$} & $\mathbf{A}^{\mathbf{c}}$ & AVE $^{\mathbf{d}}$ \\
\cline { 2 - 6 } & $\mathbf{( 1 )}$ & $\mathbf{( 2 )}$ & $\mathbf{( 3 )}$ & $\mathbf{( 4 )}$ & $\mathbf{( 5 )}$ & & & \\
\hline (1) $\mathrm{SRH}$ & $0.92 \mathrm{a}$ & & & & & 0.915 & 0.810 & 0.84 \\
(2) $\mathrm{PDH}$ & -0.15 & 0.73 & & & & 0.847 & 0.825 & 0.53 \\
(3) EA & 0.29 & -0.11 & 0.83 & & & 0.971 & 0.968 & 0.69 \\
(4) GDH & 0.38 & 0.05 & 0.18 & 0.77 & & 0.858 & 0.780 & 0.60 \\
(5) $\mathrm{EH}$ & 0.40 & -0.01 & 0.61 & 0.43 & 0.82 & 0.895 & 0.840 & 0.68 \\
\hline
\end{tabular}

Note: $\mathrm{SRH}=$ self-rated health; $\mathrm{PDH}=$ poor dietary habits; $\mathrm{EA}=$ exercise attitude; $\mathrm{GDH}=$ good dietary habits; $\mathrm{EH}=$ exercise habits; ${ }^{\mathrm{a}}$ square root of AVE. ${ }^{\mathrm{b}}$ Composite reliability $\left(\rho_{c}\right)=\left(\Sigma \lambda_{i}\right)^{2} /\left[\left(\Sigma \lambda_{i}\right)^{2}+\Sigma\right.$ Var $\left.\left(\varepsilon_{i}\right)\right]$, where $\lambda_{\mathrm{i}}$ is the outer factor loading, and $\operatorname{Var}\left(\varepsilon_{i}\right)=1-\lambda_{i}$. is the measurement error or the error variance associated with the individual indicator variable(s) for that given factor [23]. ${ }^{c} \alpha=$ Cronbach Alpha [22]. ${ }^{\mathrm{d}}$ Average variance extracted $(\mathrm{AVE})=\left(\Sigma \lambda^{2}{ }_{i}\right) /\left[\left(\Sigma \lambda^{2}{ }_{i}\right)+\Sigma \operatorname{Var}\left(\varepsilon_{i}\right)\right]$, where $\lambda_{\mathrm{i}}$ is the outer factor loading, and $\operatorname{Var}\left(\varepsilon_{i}\right)=1-\lambda_{i}$, is the measurement error or the error variance associated with the individual indicator variable(s) for that given factor [23].

\subsection{Structural Model}

The path coefficients in Table 2 and Figure 1 answer the following questions: (1) Are the dietary behavior variables directly related to SRH? The answer is yes to both good and poor dietary habits. GDH is positively related to SRH $(\beta=0.277, p<0.001)$ and PDH is negatively related to SRH ( $\beta=-0.169, p<0.001)$. Effect size and predictive relevance all indicated both GDH and PDH had predictive power on SRH. (2) Are the exercise attitude variables directly related to exercise habits? The answer is exercise attitude had significant predictive power on exercise habits $(\beta=0.611, p<0.001$ and $R^{2}=0.337$ ). (3) Are the health behavior variables directly related to BMI? PDH is negatively related to BMI $(\beta=-0.114, p<0.001)$, and GDH was related to BMI $(\beta=0.061, p<0.001)$. (4) Are the exercise habit variables directly related to BMI? The answer is yes. Exercise habit was related to BMI $(\beta=-0.137, p<0.001)$. (5) Is BMI directly related to SRH? The answer is yes. BMI is related to SRH 
$(\beta=-0.136, p<0.001)$. BMI had predictive power on SRH with $f^{2}>0.02$ and $q^{2}>0.02$. (6) Does BMI mediate the relation of health behavior to SRH? The answer is no since the $\mathrm{R}^{2}$ from those predicting constructs was extremely small. Hence, BMI does not act as a mediator among them. (7) Do exercise habits mediate the relation of exercise attitude to SRH? The answer is yes, since the path coefficient from EH to SRH was statistically significant. Hence, EH acts as a mediator among them.

Table 2. Path coefficients of structural model.

\begin{tabular}{ccccccc}
\hline Path & $\beta$ & $t$ & LL95\% CI & UL95\% CI & $f^{2}$ & $\boldsymbol{q}^{2}$ \\
\hline EA->EH & $0.611^{* * *}$ & 32.111 & 0.57 & 0.65 & 0.596 & 0.302 \\
PDH->BMI & $-0.129^{* * *}$ & 3.477 & -0.21 & -0.05 & 0.017 & 0.008 \\
GDH->BMI & 0.035 & 1.202 & -0.03 & -0.01 & 0.002 & 0.000 \\
EH->BMI & -0.021 & 0.602 & -0.10 & -0.06 & 0.000 & 0.000 \\
PDH->SRH & $-0.175^{* * *}$ & 3.477 & -0.25 & -0.11 & 0.042 & 0.027 \\
GDH->SRH & $0.265^{* * *}$ & 9.715 & 0.21 & 0.32 & 0.077 & 0.052 \\
BMI->SRH & $-0.136^{* * *}$ & 3.763 & -0.20 & -0.07 & 0.024 & 0.090 \\
EH->SRH & $0.286^{* * *}$ & 11.684 & 0.23 & 0.34 & 0.090 & 0.022 \\
\hline
\end{tabular}

Note: $\mathrm{BMI}=$ body mass index; $\mathrm{SRH}=$ self-rated health; $\mathrm{PDH}=$ poor dietary habits; $\mathrm{EA}=$ exercise attitude; $\mathrm{GDH}=$ good dietary habits; $\mathrm{EH}=$ exercise habits. $t$ values and CIs are calculated through bootstrapping routine with 238 cases and 5000 samples; $f^{2}$ : effect size; $q^{2}$ : predictive relevance; LL: lower level; UL: upper level; CI: confidence interval; ${ }^{* * *} p<0.001$.

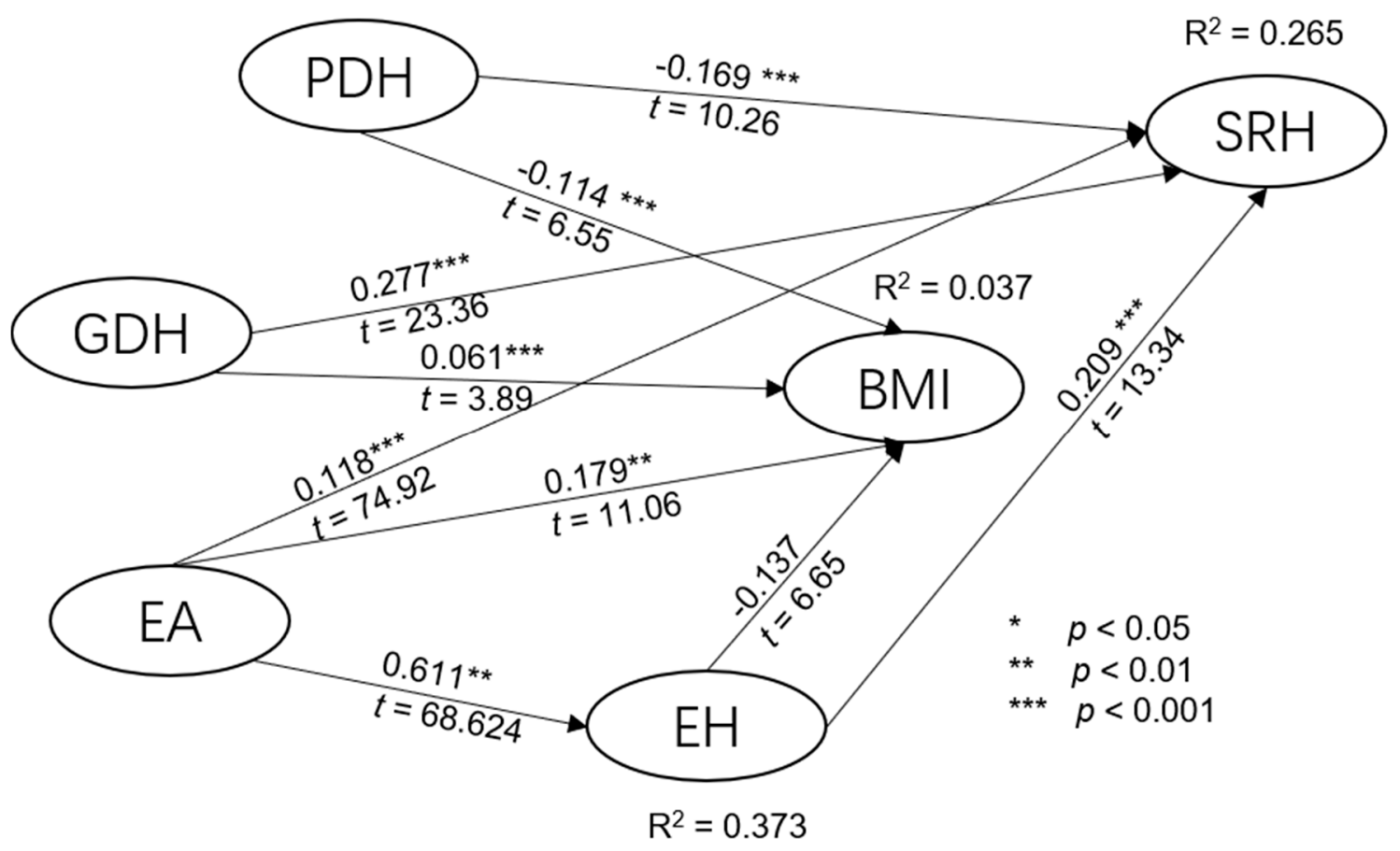

Figure 1. Structural model. BMI = body mass index; $\mathrm{SRH}=$ self-rated health; $\mathrm{PDH}=$ poor dietary habits; $\mathrm{EA}=$ exercise attitude; $\mathrm{GDH}=$ good dietary habits; $\mathrm{EH}=$ exercise habits.

Table 3 presents the direct and indirect effects and $\mathrm{R}^{2}$ of predictors to $\mathrm{EH}, \mathrm{BMI}$, and SRH. Exercise attitude predicted $37.5 \%$ of exercise habits while $\mathrm{PDH}, \mathrm{GDH}, \mathrm{EA}$, and $\mathrm{EH}$ had little predictive power on BMI $\left(\mathrm{R}^{2}=0.037\right)$. As for SRH, PDH and BMI were negatively related to SRH, while GDH, EA, and EH were all positively related to SRH. Therefore, we conclude that college students were aware of the impact of the dietary habits, exercise attitude, and exercise habits on SRH. 
Table 3. Direct and indirect effects.

\begin{tabular}{cccccc}
\hline Dependent Variable & Predicting Variable & Direct & Indirect & Total & $\mathbf{R}^{\mathbf{2}}$ \\
\hline EH & EA & 0.612 & - & 0.612 & 0.375 \\
\hline \multirow{3}{*}{ BMI } & PDH & -0.114 & - & -0.114 & \\
& GDH & 0.061 & - & 0.061 & 0.037 \\
& EH & -0.137 & - & -0.137 & \\
& EA & 0.179 & -0.084 & 0.09 & \\
SRH & PDH & -0.169 & 0.016 & -0.153 & \\
& GDH & 0.277 & -0.008 & 0.268 & \\
& BMI & -0.14 & - & -0.14 & 0.265 \\
& EH & 0.209 & 0.019 & 0.228 & \\
& EA & 0.118 & -0.025 & 0.093 & \\
\hline
\end{tabular}

Note: $\mathrm{BMI}=$ body mass index; $\mathrm{SRH}=$ self-rated health; $\mathrm{PDH}=$ poor dietary habits; $\mathrm{EA}=$ exercise attitude $\mathrm{GDH}=$ good dietary habits; $\mathrm{EH}=$ exercise habits.

\section{Discussion}

This study examined the relationships of the relative contribution of dietary habits $(\mathrm{DH})$, exercise attitude (EA), exercise habits (EH), and body mass index (BMI) to self-rated health (SRH) among college students. The results found $\mathrm{EH}, \mathrm{DH}$, and BMI explained $26.5 \%$ of SRH $\left(\mathrm{R}^{2}=0.265\right)$, which is consistent with the study found in Sweden [28], in which the authors suggested that the levels of exercise and total physical activity were significantly associated with SRH. Taking a closer look at the path coefficients of the predictive variables, we can see that the PDH and BMI values are all negative, indicating that poor dietary habits and being overweight led to bad health status. On the other hand, GDH, EA, and EH are positively related to SRH, indicating that college students with good dietary habits and exercise habits were in better SRH status. As for the relationship of PDH, GDH, EH, and $\mathrm{BMI}$, the test showed little predictive power of PDH, GDH, and EH on BMI. Finally, the relationship between EA and EH is highly correlated with an $\mathrm{R}^{2}$ of 0.375 , indicating college students with high exercise attitude perception would also have good exercise habits, which is consistent with Dishman, Sallis, and Orenstein [29].

\section{Conclusions}

This study found that dietary habits, exercise habits, and BMI all contributed to self-rated health. Test results indicated that poor dietary habits and being overweight led to bad health status. On the other hand, good dietary habits and good exercise habits led to better health status. Among those variables, $\mathrm{PDH}, \mathrm{GDH}, \mathrm{EH}$, and $\mathrm{BMI}$ all had significant positive contributions to SRH. Therefore, knowledge of healthy diet, promotion of regular exercises, refraining from poor dietary habits, and weight control may be beneficial for college student for maintaining a healthy condition.

\section{Limitations and Relevance for Future Investigations}

This study simply used BMI as a body composition indicator. Even though BMI can be used as a convenient indicator of obesity, body fat rate is a more accurate indicator of body composition. Therefore, the suggestion is made to use body fat rate and BMI as indicators of body composition. As for students' majors, further investigations of students' majors can be conducted to test if students in a health-related major may influence results.

Author Contributions: Conceptualization, H.-H.H. and C.-M.C.; Methodology, H.-H.H. and C.-M.C.; Software, H.-H.H. and C.-M.C.; Validation, H.-H.H., C.-M.C. and L.-W.L.; Formal Analysis, H.-H.H.; Investigation, H.-H.H.; Resources, H.-H.H.; Data Curation, H.-H.H.; Writing-Original Draft Preparation, H.-H.H.; Writing-Review \& Editing, H.-H.H., C.-M.C., L.-W.L. and H.-C.H.; Visualization, H.-C.H; Supervision, C.-M.C.; Project Administration, L.-W.L.

Funding: This research received no external funding. 
Acknowledgments: We appreciated all participants in this investigations. Kindly thanks for Professor Fang-Ming Huang in National Chiayi University, Taiwan for providing suggestions in model validations.

Conflicts of Interest: The authors declare no conflict of interest.

\section{References}

1. Flegal, K.M.; Carroll, M.D.; Ogden, C.L.; Johnson, C.L. Prevalence and trends in obesity among US adults, 1999-2000. JAMA 2002, 288, 1723-1727. [CrossRef] [PubMed]

2. NIH Heart, Lung, and Blood Institute. Clinical Guidelines on the Identification, Evaluation, and Treatment of Overweight and Obesity in Adults: The Evidence Report; National Institutes of Health: Bethesda, MD, USA, 1998.

3. WHO. Obesity and Overweight. 2017. Available online: http://new.who.int/news-room/fact-sheets/ detail/obesity-and-overweight (accessed on 20 February 2018).

4. Shek, D.T.; Li, X. Perceived school performance, life satisfaction, and hopelessness: A 4-year longitudinal study of adolescents in Hong Kong. Soc. Indic. Res. 2016, 126, 921-934. [CrossRef] [PubMed]

5. Pan, W.H.; Wu, H.J.; Yeh, C.J.; Chuang, S.Y.; Chang, H.Y.; Yeh, N.H.; Hsieh, Y.T. Diet and Health Trends in Taiwan: Comparison of Two Nutrition and Health Surveys from 1993-1996 and 2005-2008. Asia Pac. J. Clin. Nutr. 2014, 20, 238-250. [CrossRef]

6. Yeh, C.S.; Lin, Y.H.; Chen, C.A. Dietary Habits Effect on the Body Mass Index Trends of College Students. Mackay J. 2013, 11, 51-70.

7. Mossey, J.M.; Shapiro, E. Self-rated health: A predictor of mortality among elderly. Am. J. Public Health 1982, 72, 800-808. [CrossRef] [PubMed]

8. Sing-Manoux, A.; Martikainen, P.; Ferrie, J.; Zins, M.; Marriot, M.; Goldberg, M. What does self-rated health measure? Results from the British Whitehall II and French Gazel cohort studies. J. Epidemiol. Community 2006, 60, 364-372.

9. Chang, M. Address to Freshmen. 2014. Available online: https://www.cw.com.tw/article/article.action?id= 5012852 (accessed on 21 April 2018).

10. Wu, S.; Wang, R.; Zhao, Y.; Ma, X.; Wu, M.; Yan, X.; He, J. The relationship between self-rated health and objective health status: A population-based study. BMC Public Health 2013, 13, 320. [CrossRef] [PubMed]

11. Deshpande, S.; Basil, M.D.; Basil, D.Z. Factors Influencing Healthy Eating Habits Among College Students: An Application of the Health Belief Model. Health Mark. Q. 2009, 26, 145-164. [CrossRef] [PubMed]

12. Godin, G.; Shephard, R.J. Psychosocial Factors Influencing Intentions to Exercise of Young Students from Grades 7 to 9. Res. Q. Exerc. Sport 2013, 57, 41-52. [CrossRef]

13. Ryan, E.R.; Kerry, S.C.; Lee, W.J. Personality and social cognitive influences on exercise behavior: Adding the activity trait to the theory of planned behavior. Psychol. Sport Exerc. 2004, 5, 243-254.

14. Hiza, H.A.; Pratt, C.; Mardis, A.L.; Anand, R. Body mass index and health. Fam. Econ. Nutr. Rev. 2001, 13, 52.

15. Calle, E.E.; Thun, M.J.; Petrelli, J.M.; Rodriguez, C.; Heath, C.W., Jr. Body-mass index and mortality in a prospective cohort of US adults. N. Engl. J. Med. 1999, 341, 1097-1105. [CrossRef] [PubMed]

16. Yang, L.M.; Ku, Y.C. The development and application of exercise attitude scale for university students. Phys. Educ. J. 2004, 37, 149-162.

17. Fox, K.R. Physical Self-Perceptions and Exercise Involvement. Ph.D. Thesis, Arizona State University, Phoenix, AZ, USA, 1987.

18. Huang, C.T. Study on the Healthy Lifestyle and Related Factors of Police in Taipei City. Master's Thesis, National Taiwan Normal University, Taipei, Taiwan, 2009.

19. Esposito Vinzi, V.; Chin, W.W.; Henseler, J.; Wang, H. Handbook of Partial Least Squares: Concepts, Methods and Applications; Springer Handbooks of Computational Statistics Series; Springer: Heidelberg, Germany; Dordrecht, The Netherlands; London, UK; New York, NY, USA, 2010; Volume II, Available online: https://www.smartpls.com/documentation/literature/books (accessed on 23 April 2018).

20. Sallis, J.F. Progress in behavioral research on physical activity. Ann. Behav. Med. 2001, 23, 77-78. [CrossRef] [PubMed]

21. Ringle, C.M.; Wende, S.; Will, A. SmartPLS 2.0.M3; SmartPLS: Hamburg, Germany, 2005.

22. Pirouz, D.M. An Overview of Partial Least Squares. 2006. Available online: http://ssrn.com/abstract= 1631359 (accessed on 26 February 2018). 
23. Hair, F.J.; Sarstedt, M.; Hopkins, L.; Kuppelwieser, G.V. Partial least squares structural equation modeling (PLS-SEM) An emerging tool in business research. Eur. Bus. Rev. 2014, 26, 106-121. [CrossRef]

24. Cronbach, L.J. Coefficient Alpha and the internal structure of tests. Psychometrika 1951, 16, $297-333$. [CrossRef]

25. Fornell, C.; Larcker, D.F. Evaluating structural equation models with unobservable variables and measurement error. J. Mark. Res. 1981, 18, 39-50. [CrossRef]

26. Wetzels, M.; Odekerken-Schröder, G.; Van Oppen, C. Using PLS path modeling for assessing hierarchical construct models: Guidelines and empirical illustration. MIS Q. 2009, 33, 177-195. [CrossRef]

27. Henseler, J.; Sarstedt, M. Goodness-of-fit indices for partial least squares path modeling. Comput. Stat. 2013, 28, 565-580. [CrossRef]

28. Södergren, M.; Sundquist, J.; Johansson, S.E.; Sundquist, K. Physical activity, exercise and self-rated health: A population-based study from Sweden. BMC Public Health 2008, 8, 352. [CrossRef] [PubMed]

29. Dishman, R.K.; Sallis, J.F.; Orenstein, D.R. The determinants of physical activity and exercise. Public Health Rep. 1985, 100, 158-171. [PubMed]

(C) 2018 by the authors. Licensee MDPI, Basel, Switzerland. This article is an open access article distributed under the terms and conditions of the Creative Commons Attribution (CC BY) license (http://creativecommons.org/licenses/by/4.0/). 